\title{
POTENSI JENIS LEBAH MADU KELULUT (Trigona spp) UNTUK MENINGKATKAN EKONOMI MASYARAKAT DESA GALANG KECAMATAN SUNGAI PINYUH KABUPATEN MEMPAWAH
}

\author{
(Potential Of The Type Of Honey Bee (Trigona Spp) To Improve The Economy Of The \\ Community In The Village Of Sungai Pinyuh Mempawah Regency) \\ Lukman, Gusti Hardiansyah, Sarma Siahaan \\ Fakultas Kehutanan Universitas Tanjungpura Jl. Daya Nasional, Pontianak 78124 \\ Email: Lukmancs.611@gmail.com
}

\begin{abstract}
The Trigona bee is a small black insect with a body length of 3-4 mm and a wingspan of $8 \mathrm{~mm}$. East Kalimantan has found Trigona spp bees, namely T. laeviseps, T. apicalis, T. Drescheri. T. fucibasis, T. fuscobalteata, T. insica, T. itama, T. melina and T. terminate. This study aims to determine the potential of kelulut honey bees (Trigona spp) in the community honey farmer group of Galang Sungai Pinyuh Village, Mempawah Regency, to identify the types of kelulut bees (Trigona spp) in the box (stup) that made by the honey farmer group of Galang Village. Sungai Pinyu, Mempawah Regency, Analyzing the additional economic income of the Galang Village community, Sungai Pinyuh District, Mempawah Regency. This research was conducted in Galang Sungai Pinyuh Village Mempawah Regency which was conducted for 1 month in the field, by using the survey method, by using the method, which is the activity of finding the existence of a species that is the object of bee research. There are 2 types of Trigona spp bees cultivated in the Galang Kelulut Honey Forest Farmers Group, namely H. itama Cockerel, and H. bakeri, and processing of kelulut honey (Trigona spp) will benefit greatly from the services of kelulut honey (Trigona spp). Harvesting of kelulut honey from honey farmers is 15-30 liters / month. The selling price for consumers is around IDR 400,000 for every 1 liter. From the research above, it is concluded that the potential of kelulut honey bees (Trigona spp) can increase the income of the people of Galang Village, Sungai Pinyuh District, Mempawah Regency.
\end{abstract}

Keywords: Community economy, Potency, Trigona.

\section{PENDAHULUAN}

Lebah pekerja memiliki kepala besar dan rahang panjang. Sedangkan lebah ratu berukuran 3-4 kali ukuran pekerja, perut besar mirip Laron, berwarna kecoklatan dan mempunyai sayap pendek. Lebah ini tidak mempunyai sengat (stingless bee). Lebah Trigona yang dikenal dengan kelulut di Kalimantan ini mudah ditemukan di lingkungan sekitar (Mahani et al. 2011).

Madu adalah cairan alami yang umumnya rasa manis yang dihasilkan oleh lebah madu dari sari bunga tanaman atau bagian lain dari tanaman atau ekskresi serangga (Gebremarian 2014). Madu kelulut (Trigona spp) dibudidayakan oleh Kelompok Tani Hutan Madu Kelulut Galang, namun masyarakat belum banyak mengenal potensi jenis lebah madu kelulut (Trigona spp). Berdasarkan banyaknya keunggulan dan kelebihan lebah kelulut (Trigona spp) yang ada serta belum terimbanginya industri perlebahan yang ada dalam meningkatkan ekonomi masyarakat maka perlu dilakukan penelitian potensi jenis lebah madu kelulut (Trigona spp), ukuran kotak (stup) dan jenis apa saja yang ada di dalam kotak (stup). 
Berdasarkan penelitian oleh Syafriza et al. (2014) yang dilakukan di hutan lempake, Kalimatan Timur menemukan jenis lebah Trigona spp yaitu T. laeviseps, T. apicalis, T. Drescheri. T. fucibasis, $T$. fuscobalteata, T. insica, T. itama, T. melina dan T. terminate. Romi Wardoyo (2016) menunjukkan bahwa usaha ternak lebah madu Jaya Makmur memperoleh pendapatan sebesar Rp 3.899.510 per satu periode produksi. Usaha ternak lebah madu Jaya Makmur di Desa Jono Oge Kecamatan Sigi Biromaru Kabupaten Sigi layak diusahakan.

Tujuan penelitian adalah untuk mengetahui potensi jenis lebah madu kelulut (Trigona spp) pada Kelompok Tani Hutan Madu Kelulut Galang, mengidentifikasi jenis lebah kelulut (Trigona spp) di dalam kotak (stup), menganalisis pendapatan tambahan ekonomi masyarakat Desa Galang Kecamatan Sungai Pinyuh Kabupaten Mempawah.

\section{METODE PENELITIAN}

Alat - alat yang digunakan adalah peta lokasi kegiatan penelitian, kamera (hp oppo), sebagai alat untuk dokumentasi, buku pengamatan untuk mencatat data dilapangan, buku panduan identifikasi lebah kelulut Trigona spp (Indo-Malayan Stingless Bees), kotak specimen untuk menyimpan sampel lebah Trigona spp, alcohol $70 \%$ untuk pengawetan serangga, jarum digunakan untuk membuat insectarium, dan kaliper untuk mengukur diameter lebah Trigona spp.

Penelitian dilaksanakan pada tanggal 05 Februari 2020 sampai 05 Maret 2020. Objek dalam penelitian ini adalah lebah madu kelulut (Trigona spp). Pelaksanaan penelitian ini menggunakan metode survey yaitu kegiatan mencari keberadaan spesies yang menjadi objek penelitian lebah kelulut. Subjek dalam penelitian ini yaitu Kelompok Tani Hutan Madu Kelulut Galang. Jenis data yang dikumpulkan dalam penelitian ini adalah data atau informasi yang berhubungan dengan potensi jenis lebah madu kelulut (Trigona spp) untuk meningkatkan ekonomi masyarakat Desa Galang Sungai Pinyuh Kabupaten Mempawah. Jumlah responden dalam penelitian ini sebanyak 15 orang reponden dari Kelompok Tani Hutan Madu Kelulut Galang. Data yang diperoleh dari lapangan disajikan dalam bentuk tabulasi, gambar dan foto kemudian analisis dengan deskriptif.

\section{Matrik Penelitian}

Berdasarkan tujuan yang telah ditentukan sebelumnya, maka dibawah ini merupakan tabel untuk melihat keterkaitan antara tujuan, sumber data, metode analisis data yang digunakan. 
Tabel 1. Matrik Penelitian (Research Matrix)

\begin{tabular}{|c|c|c|c|c|}
\hline No & Tujuan & Sumber Data & Motode & Analisis Data \\
\hline 1 & $\begin{array}{l}\text { Bagaimana mendapatkan potensi jenis } \\
\text { lebah madu kelulut (Trigona spp) yang } \\
\text { ada di kelompok petani madu } \\
\text { masyarakat Desa Galang Kecamatan } \\
\text { Sungai Pinyuh Kabupaten Mempawah. }\end{array}$ & $\begin{array}{l}\text { Pontensi jenis kelulut (Trigona } \\
\text { spp) mana yang paling banyak } \\
\text { dibudidayakan dan pendapatan } \\
\text { Kelompok Tani Hutan Madu } \\
\text { Kelulut Galang. }\end{array}$ & $\begin{array}{l}\text { Deskriptif } \\
\text { Kualitatif }\end{array}$ & $\begin{array}{l}\text { Menggunakan } \\
\text { tabulasi, foto } \\
\text { dan kemudian } \\
\text { diamati secara } \\
\text { deskriptif. }\end{array}$ \\
\hline 2 & $\begin{array}{l}\text { Mengidentifikasi jenis lebah kelulut } \\
\text { (Trigona spp) di dalam kotak (stup) } \\
\text { yang di buat kelompok petani madu } \\
\text { Desa Galang Kecamatan Sungai Pinyu } \\
\text { Kabupaten Mempawah. }\end{array}$ & $\begin{array}{l}\text { Jumlah jenis dan koloni lebah } \\
\text { kelulut (Trigona spp) } \\
\text { dibudidayakan Kelompok } \\
\text { Hutan Madu Kelulut Galang }\end{array}$ & $\begin{array}{l}\text { Deskriptif } \\
\text { Kualitatif }\end{array}$ & $\begin{array}{l}\text { Menggunakan } \\
\text { tabulasi, foto } \\
\text { kemudian } \\
\text { diamati secara } \\
\text { deskriptif }\end{array}$ \\
\hline 3 & $\begin{array}{l}\text { Apakah dengan usaha lebah madu } \\
\text { kelulut (Trigona spp) bisa meningkatkan } \\
\text { ekonomi masyarakat Desa Galang } \\
\text { Kecamatan Sungai Pinyuh Kabupaten } \\
\text { Mempawah }\end{array}$ & $\begin{array}{l}\text { Pendapatan masyarakat perbulan } \\
\text { dengan membudidayakan madu } \\
\text { kelulut (Trigona spp). }\end{array}$ & $\begin{array}{l}\text { Deskriptif } \\
\text { Kualitatif }\end{array}$ & $\begin{array}{l}\text { Menggunakan } \\
\text { tabulasi, foto } \\
\text { kemudian } \\
\text { diamati secara } \\
\text { deskriptif }\end{array}$ \\
\hline
\end{tabular}

HASIL DAN PEMBAHASAN

Jenis Pakan untuk Budidaya Trigona spp

Berdasarkan hasil wawancara dengan Kelompok Tani Hutan Madu
Kelulut Galang terdapat tumbuhan atau tanaman yang tumbuh di sekitar pekarangan dan halaman rumah yang menjadi pakan Trigona spp. Dapat dilihat pada Tabel 2 dibawah ini.

Tabel 2. Potensi Pakan yang Tersedia (Potential Available Feed)

\begin{tabular}{|c|c|c|c|c|c|c|c|}
\hline \multirow[t]{2}{*}{ No } & \multicolumn{7}{|c|}{ Tanaman atau Pohon } \\
\hline & $\mathrm{B}$ & $\mathrm{D}$ & $\mathrm{K}$ & $\mathrm{L}$ & $\mathrm{N}$ & $\mathrm{R}$ & $\mathrm{S}$ \\
\hline 1 & $\begin{array}{l}\text { Bunga air mata } \\
\text { pengantin, kemuning }\end{array}$ & - & Karet & Lengkeng & - & - & - \\
\hline 2 & $\begin{array}{l}\text { Bunga air mata } \\
\text { pengantin }\end{array}$ & Durian & - & - & - & Rambutan & - \\
\hline 3 & $\begin{array}{l}\text { Bunga air mata } \\
\text { pengantin }\end{array}$ & - & Karet & Lengkeng & - & - & - \\
\hline 4 & $\begin{array}{l}\text { Bunga air mata } \\
\text { pengantin, kemuning }\end{array}$ & Durian & - & - & Nanas & & Sawo \\
\hline 5 & $\begin{array}{l}\text { Bunga air mata } \\
\text { pengantin }\end{array}$ & - & - & Lengkeng & _- & Rambutan & - \\
\hline 6 & $\begin{array}{l}\text { Bunga air mata } \\
\text { pengantin, kemuning }\end{array}$ & Durian & - & - & Nanas & - & - \\
\hline 7 & $\begin{array}{l}\text { Bunga air mata } \\
\text { pengantin }\end{array}$ & - & - & Lengkeng & - & Rambutan & \\
\hline 8 & $\begin{array}{l}\text { Bunga air mata } \\
\text { pengantin, kemuning }\end{array}$ & - & Karet & - & - & Rambutan & - \\
\hline 9 & $\begin{array}{l}\text { Bunga air mata } \\
\text { pengantin, kemuning }\end{array}$ & Durian & _- & - & Nanas & - & Sawo \\
\hline 10 & $\begin{array}{l}\text { Bunga air mata } \\
\text { pengantin }\end{array}$ & - & - & - & Nanas & Rambutan & - \\
\hline 11 & $\begin{array}{l}\text { Bunga air mata } \\
\text { pengantin }\end{array}$ & Durian & _- & Lengkeng & - & Rambutan & - \\
\hline 12 & $\begin{array}{l}\text { Bunga air mata } \\
\text { pengantin }\end{array}$ & Durian & Karet & - & - & - & Sawo \\
\hline 13 & $\begin{array}{l}\text { Bunga air mata } \\
\text { pengantin }\end{array}$ & - & _- & - & Nanas & - & - \\
\hline 14 & $\begin{array}{l}\text { Bunga air mata } \\
\text { pengantin, kemuning }\end{array}$ & - & Karet & _- & Nanas & - & - \\
\hline 15 & $\begin{array}{l}\text { Bunga air mata } \\
\text { pengantin }\end{array}$ & - & _- & Lengkeng & Nanas & - & - \\
\hline
\end{tabular}


Berdasarkan Tabel 2. hasil wawancara dengan masyarakat sekitar hutan Desa Galang terdapat tumbuhan atau tanaman yang tubuh di sekitar pekarangan dan halaman rumah masyarakat yang berpotensi menjadi pakan Trigona spp. bahwa semua kelompok tani hutan madu kelulut Galang atau responden memiliki lahan yang ditumbuhi tanaman dan tumbuhan penghasil nektar dan pollen disekitar pekarangan rumah yang berpotensi sebagai pakan lebah Trigona spp. Lebah madu merupakan kelompok serangga yang berperan sebagai agen polinato tanaman berbunga, meningkatkan produksi tanaman tersebut (Corlett 2011). Lebah madu dan tanaman berbunga memiliki hubunga yang saling menguntungkan yaitu tanaman sebagai penyedia pakan lebah berupa nektar dan polen, sedangkan lebah madu melakukan proses polinasi tanaman tersebut.

\section{Jenis Kelulut (Trigona spp)}

Dari hasil penelitian diperoleh identifikasi jenis kelulut (Trigona spp) di dalam kotak (Stup).

Tabel 3. Identifikasi Jenis Kelulut (Trigona spp) di Dalam Kotak (Stup) (Identify The Type Of (Trigona spp) In The Box).

\begin{tabular}{lllc}
\hline No & \multicolumn{1}{c}{ Jenis Lebah } & \multicolumn{1}{c}{ Trigona spp } \\
\hline \multicolumn{1}{c}{ Nama Daerah } & Spesies & Jumlah Koloni \\
\hline 1 & Kelulut hitam, kelulut hitam besar & H. bakeri, H. itama Cockerell & 215 \\
2 & Kelulut hitam & H. itama Cockerell & 41 \\
3 & Kelulut hitam & H. itama Cockerell & 120 \\
4 & Kelulut hitam & H. itama Cockerell & 60 \\
5 & Kelulut hitam & H. itama Cockerell & 50 \\
6 & Kelulut hitam & H. itama Cockerell & 53 \\
7 & Kelulut hitam & H. itama Cockerell & 50 \\
8 & Kelulut hitam & H. itama Cockerell & 55 \\
9 & Kelulut hitam & H. itama Cockerell & 85 \\
10 & Kelulut hitam & H. itama Cockerell & 50 \\
11 & Kelulut hitam & H. itama Cockerell & 50 \\
12 & Kelulut hitam & H. itama Cockerell & 46 \\
13 & Kelulut hitam & H. itama Cockerell & 52 \\
14 & Kelulut hitam & H. itama Cockerell & 45 \\
15 & Kelulut hitam & H. itama Cockerell & 43 \\
\hline Total & & & 1015 \\
\hline Rata-Rata & & & 67,7 \\
\hline
\end{tabular}

Berdasarkan Tabel 3. hasil penelitian bahwa lebah kelulut (Trigona spp) yang berhasil teridentifikasi dari kelompok tani hutan madu kelulut Galang, adalah 4 jenis yaitu: Heterotrigona itama Cockerel, Heterotrigona bakeri, Tragonula laeviceps Smith, Geniotrogona lacteifasciata Cameron.

Koloni yang paling banyak di budidayakan oleh Kelompok Tanih Hutan Madu Kelulut Galang adalah jenis H. itama Cockerell berjumlah 1000 koloni sedangkan jenis $H$. bakeri berjumlah 15 koloni karana jenis ini 
cepat beradaptasi dengan lingkungan yang baru, paling banyak menghasilkan madu di bandikan jenis yang lain. Menurut Kerisna (2019) jenis lebah Trigona spp yang berasil ditemukan pada zona pemanfaatan hutan Desa Menua Sadap Kecamatan Embaloh Hulu kabupaten Kapuas Hulu berjumlah 8 jenis yaitu: G. lacteifasciata Cameron, $T$. binghami Schwarz, H. itama Cockerell, T. collina Smith, L. terminate Smith, $T$. sirindhornae Michener \& Boongird, $T$. laeviceps Smith, T. Fuscobaltaeta Cameron dan jumlah koloni sekitar 56 koloni.

Perbandingan ukuran jenis kelulut yang di temukan yaitu ukuran tubuh lebah kelulut dapat dilihat dari bentuk ukuran yang paling besar sampai ke ukuran yang paling kecil untuk ukuran yang paling besar yaitu jenis Geniotrigona lacteifasciata Cameron sedangkang ukurang yang paling kecil yaitu Tetragonula laeviceps Smith (1. Kelulut merah (Geniotrigona lacteifasciata Cameron), 2. Kelulut hitam besar (Heterotrigona bakeri), 3. Kelulut hitam (Heterotrigona itama Cockerell), dan 4. Kelulut hitam kecil (Tetragonula laeviceps Smith). Syafrizal et al. (2014) menyatakan bahwa ukuran tubuh sangat mempengaruhi jarak terbang lebah mencari makanan. Semakin besar tubuh lebah maka makin jauh jarak terbangnya. Trigona spp dengan ukuran $5 \mathrm{~cm}$ mempunyai jarak terbang sekitar $600 \mathrm{~m}$.

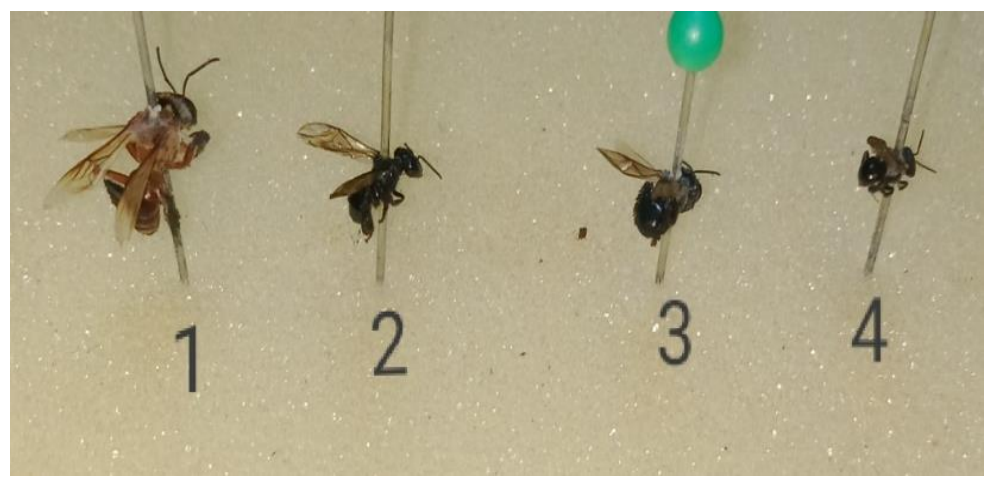

Gambar 1. Perbandingan Ukuran Tubuh Tiap Jenis Lebah Kelulut (Trigona spp) (Comparison Of Body Size Of Each Type Of Bees (Trigona spp).

Perbandingan bentuk pintu masuk jenis lebah Trigona spp yang ditemukan di Kelompok Tani Hutan Madu Kelulut Galang adalah jenis kelulut hitam Heterotrigona bakeri memiliki ciri khas tersendiri dimana lebah pekerja menjaga corong di dalam, kelulut Heterotrigona itama Cockerell sangat aktif di luar corong sedangkan Tetragonula laeviceps Smith bentuk corong seperti sarang semut berwarna putih hitam. 


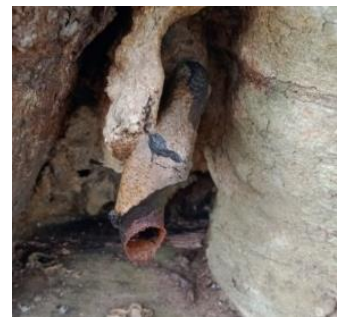

(1)

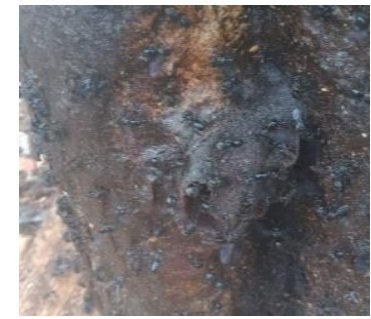

(2)

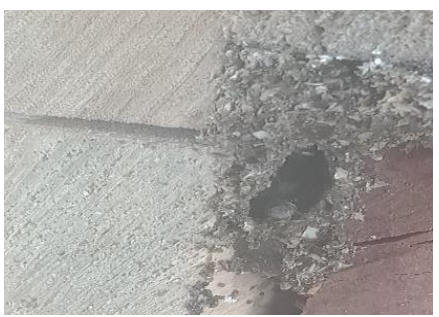

(3)

Gambar 2. Bentuk Pintu Masuk Kelulut Hitam Besar (H. bakeri) (1), Bentuk Pintu Masuk Kelulut Hitam (H. itama Cockerell) (2), dan Bentuk Pintu Masuk Kelulut Hitam Kecil (T. laeviceps Smith) (3). (Large Black Entrance (H. bakery) (1), Black Entrance Form (Black Cockerell) (2), And The Shepe Of A Small Black Entrance (T. Laeviceps Smith) (3).

\section{Ukuran Stup}

Stup atau rumah lebah di buat agar lebah aman/nyaman betah tinggal disarangnya dan memudahkan pemanenan produk pelebahan. Karena itu bahan dan ukuran pun berbeda - beda di Desa Galang. Di Desa Galang ada dua ukuran yang berbeda - beda. Namun secara umum prinsipnya sama yaitu memamfaatkan bahan lokal, nyaman dan tahan lama. Bahan stup menggunakan papan kayu medang kering, tidak berbau, bebas bahan kimia dan memiliki kekuatan keawetan baik, ketebalan papan $2 \mathrm{~cm}$ yaitu untuk menjaga kelembaban dan stabilitas sarang, jika kayu yang digunakan ketebalannya kurang dari $2 \mathrm{~cm}$, kebanyakan koloni kelulut akan pergi meninggalkan sarangnya. Paling banyak menghasilkan madu ukuran 38 x 25 x $10 \mathrm{~cm}$ sedangkan yang paling sedikit menghasilkan madu ukuran 42 x 25 x $10 \mathrm{~cm}$ karena kotaknya terlalu besar, kotaknya tidak rapat masih ada rongga seringga semut bisa masuk. Stup ditempatkan pada lokasi yang teduh terlindung sinar matahari langsung dan air.
Ukuran yang paling besar memiliki 15 koloni dan ukuran yang paling kecil memiliki 1000 koloni dari Kelompok Tani Huta Madu Kelulut.

Selamak proses budidaya lebah Trigona spp, kegiatan pemeliahaan yang perlu dilakukan adalah pembersihan stup dan sekitarnya dari kotoran, untuk menghindari pengganggu lebah datang, menjaga lebah madu Trigona dari gangguan serangga lain seperti semut, laba - laba dan tawon liar dengan cara penyeprotan begen racun serangga, pengecekan koloni lebah setiap dua pekan atau setiap bulan memastikan perkembangan dan kesehatan. Menurut Dewantari (2019) rancang bangun stup lebah Trigona $s p$ dibuat menggunakan kayu hutan yang berserat halus seperti albisia atau kayu pandan hutan dengan ukuran standar yang digunakan $40 \mathrm{x} 20 \mathrm{x}$ $15 \mathrm{~cm}$ dan $30 \times 15 \times 10 \mathrm{~cm}$ berbentuk kotak sehingga disebut stup sistem kotak. Stup kotak Trigona spp bisa digantung ataupun disusun pad arak dan diletakkan di tempat teduh, tidak terkena hujan dan sinar 
matahari langsung. Pemeliharaan stup dilakukan secara rutin dan periodik, meliputi pembersihan dari sarang semut / laba - laba, pengecekan kondisi stup agar tidak terkena air hujan. Stup juga harus dihindarkan dari hama pengganggu sepeti cecak, tokek, larva kumbang, tawon kuning, ayam dan lain lain. Sebanyak $80 \%$ dari total anggota kelompok atau sekitar 16 orang anggota kelompok mampu membuat rancang bangun stup sistem kotak dengan baik.

\section{Proses Pengelolaan Madu Kelulut (Trigona spp)}

Kelompok Tanih Hutan Madu Kelulut Galang dalam hal pemanenan dan pengelolaan madu kelulut di berikan pembinaan dan pendampingan dari instruktur Kelompok Tani Hutan (KTH) melalui metode penen lestari, dan penerapan mekanisme pengawasan mutu kelompok (Internal control sistem ICS) madu yang di hasilkan dari madu kelulut (Trigona spp) asam manis karena mengambil serbuk sari bunga nenas seringga madu yang di hasilkan sangat masam memiliki aroma nenas di bandikan dengan madu kelulut di tempat lain. Kelompok Tani Hutan Madu Kelulut Galang menggunakan mesin penyedot madu kelulut (Trigona spp) dan menggunakan saringan sampai madu menetes semua. Sistem ini bisa membuat madu tahan lama, rasanya tetap terjaga, warna tetap jernih, rasa madu asam manis dan madu kelulut higienis sangat aman untuk kesehatan.

Proses panen Kelompok Tani Hutan Madu Kelulut Galang menggunakan semua peralatan termasuk Kotak (stup), peralatan yang steril mensin penyedot, jerigen 10 liter dan tabung kecil filter madu sebelum memanen madunya, botol di cuci terlebih dahulu bertujuan untuk menjaga kualitas madu agar kualitas dan mutunya tetap terjaga. Madu kelulut tidak boleh dipanen semua jika dipanen semua kelulut bisa setres harus ada yang ditinggalkan 10 $\%$ supaya kelulut memproduksi lagi.

Madu dengan kualitas dan bermutu baik ini membuat harga madu memili dijual dengan harga setempat Rp 400.000 oleh Kelompok Tani Hutan Madu Kelulut Galang. Madu di masukan ke dalam botol sebanyak 1 liter dan di beri label madu kelulut assyifa. Madu yang dikemas dalam botol ini di jual dengan harga Rp 400.000 perbotolnya. Hal ini menjadi penghasilan tambahan bagi masyarakat Kelompok Tani Madu Kelulut selain berkerja sebagai petani untuk dapat meningkatkan perekonomian serta memenuhi kebutuhan masyarakat. Menurut Awaludin (2018) yang dilakukan di Kebun Raya Universitas Halu Oleo, jenis lebah kelulut (Trigona spp) yang dibudidayakan adalah Trigona itama, yang mempunyai beberapa keunggulan yaitu mudah dibudidayakan, lebah tidak mempunyai sengat, koloni lebah banyak menghasilkan madu, kotak sarang lebah mudah dibuat dan harganya relative murah, dan harga madu lebih mahal dibandingkan jenis aphis. Nilai manfaat lebah madu kelulut (Trigona spp) hasil budidaya berkisar antara Rp 500.000 s.d Rp 1.000.000 per koloni/stup. Potensi pengembangan lebah madu kelulut (Trigona spp) masih tinggi. Harga madu berkisar antara Rp 500.000 s.d Rp 1.000 .000 per kg. Sementara untuk raw 
propolis, harganya sekitar Rp 400.000 s.d Rp 600.000 per kg. Harga madu Kebun Raya Universitas Halu Oleo Rp 500.000 s.d Rp 1.000.000 per kg.

\section{Nilai Ekonomi Kelulut (Trigona spp)}

Dari hasil penelitian diperoleh nilai ekonomi madu kelulut yang dilakukan oleh Kelompok Tanih Hutan Madu Kelulut Galang.

Tabel 4. Manfaat Nilai Ekonomi Kelulut (Trigona spp) (Benefits Of Economic Valuen (Trigona spp)

\begin{tabular}{lccccc}
\hline No & $\begin{array}{l}\text { Jumlah madu } \\
\text { itama (liter) }\end{array}$ & $\begin{array}{l}\text { Jumlah madu } \\
\text { bakeri (liter) }\end{array}$ & Harga/liter (Rp) & $\begin{array}{l}\text { Pendapatan } \\
\text { sebelum ada } \\
\text { madu (Rp) }\end{array}$ & $\begin{array}{l}\text { Pendapatan } \\
\text { ada madu (Rp) }\end{array}$ \\
\hline 1 & 20 & 10 & 400.000 & 4.500 .000 & 12.000 .000 \\
2 & 20 & - & 400.000 & & 8.000 .000 \\
3 & 30 & - & 400.000 & 4.850 .000 & 12.000 .000 \\
4 & 30 & - & 400.000 & 3.700 .000 & 12.000 .000 \\
5 & 20 & - & 400.000 & 3.600 .000 & 8.000 .000 \\
6 & 15 & - & 400.000 & 5.350 .000 & 6.000 .000 \\
7 & 15 & - & 400.000 & 2.050 .000 & 6.000 .000 \\
8 & 10 & - & 400.000 & 4.250 .000 & 4.000 .000 \\
9 & 10 & - & 400.000 & 4.600 .000 & 4.000 .000 \\
10 & 15 & - & 400.000 & 4.050 .000 & 6.000 .000 \\
11 & 15 & - & 400.000 & 1.500 .000 & 6.000 .000 \\
12 & 20 & - & 400.000 & 4.600 .000 & 12.000 .000 \\
13 & 30 & - & 400.000 & 3.450 .000 & 12.000 .000 \\
14 & 20 & - & 400.000 & 3.450 .000 & 8.000 .000 \\
15 & 20 & - & 400.000 & 4.200 .000 & 8.000 .000 \\
\hline Total & 300 & 10 & 6000.000 & 54.150 .000 & 124.000 .000 \\
\hline Rata - rata & 20 & 0,6 & 400.000 & 3.610 .000 & 8.266 .667 \\
\hline
\end{tabular}

Berdasarkan Tabel 4. menunjukkan bahwa responden dari kelompok tani hutan madu kelulut Galang nilai ekonomi mengalami peningkatan pendapatan yang berbeda - beda dari hasil sampingan untuk penjualan madu kelulut (Trigona spp).

Pengelolaan madu kelulut (Trigona spp) dapat memberikan manfaat yang besar dari jasa madu kelulut tersebut kepada petani madu. Sebesar 15 - 30 liter/bulan. Harga yang di jual untuk para konsumen adalah sekitar Rp 400.000 untuk setiap 1 liter. Radam (2011) menyatakan bahwa produksi yang dihasilkan dengan jumlah sarang rata rata 220 sarang/orang adalah 1290 botol/sarang dengan produksi terbesar $3500 \mathrm{botol} / \mathrm{sarang}$ dan yang terkecil 500 botol/bulan. Produktivitas yang dihasilkan sebesar 5,32 botol/sarang dengan produktivitas terbesar 7 botol/sarang dan terkecil 4,6 botol/sarang. Pendapatan yang diperoleh adalah sebesar Rp 4.000.000 sedangkan pendapatan yang diperoleh adalah dari mata pencaharian pokok adalah sebesar Rp 350.000 per KK/bulan. Kontribusi pendapatan usaha madu terhadap pendapatan total sebesar $83 \%$. Produktivitas lebah madu dipengaruhi oleh besarnya sarang dalam satu koloni lebah, faktor cuaca dan sumber makanan. 
Dari penelitian diatas bahwa potensi jenis lebah madu kelulut (Trigona spp) dapat menambah pendapatan masyarakat Desa Galang Kecamatan Sungai Pinyuh Kabupaten Mempawah. Potensi jenis yang paling banyak menghasilkan madu yaitu jenis kelulut hitam (H. itama Cockerell) dibandingkan dengan jenis kelulut Hitam besar ( $H$. bakeri) menurut pendapat Kelompok Tani Hutan Madu Kelulut Galang, ukuran kotak (stup) menentukan banyak sedikit madu yang diperoleh. Kelompok Tani Hutan Madu Kelulut Galang hanya membudidayakan 2 jenis lebah madu kelulut yaitu kelulut hitam (H. itama Cockerel) dengan jenis kelulut Hitam besar (H. bakeri).

Vegetasi yang terdapat pada Kelompok Tani Hutan Madu kelulut Galang merupakan vegetasi dari hutan hujan tropis, dimana hamper semua bagian ditumbuhi keanekaragaman hayati. Dominasi tanaman buah buahan seperti jeruk, manga, rambutan, manggis, pepayah, belimbing, durian, sawo, kokosan, lengkeng, jambu air, nangka, kedondong, dan nenas. Terdapat juga berbagai tanamam perkebunan seperti kelapa, kelapa sawit, kopi, coklat, pinang, dan karet. Di pekaranggan rumah masyarakat Desa Galang menanam bunga air mata pengantin (Antigonon) untuk pakan madu kelulut karena berbunga sepanjang tahun. Menurut Igbal et al (2016) lebah Trigona spp lebah cenderung menempati pohon yang berukuran besar karena adanya naungan tajuk yang rimbun, tersedianya iklim mikro (microclimate) yang lebih sesuai dengan kehidupan Trigona spp terutama suhu dan kelembaban udara yang lebih stabil pada pohon besar serta tersedianya sumber pakan alami di daerah sekitarnya.

\section{KESIMPULAN}

1. Potensi jenis yang paling banyak menghasilkan madu yaitu jenis kelulut hitam (H. itama cockerel). Mudah beradaptasi dengan lingkungan yang baru dan mudah diperkembangbiakan. Seringga jenis kelulut hitam ( $H$. itama cockerel) yang paling banyak dibudidayakan oleh Kelompok Tani Hutan Madu Kelulut Galang.

2. Bentuk ukuran kotak (stup) menentukan banyak sedikinya madu yang diperoleh, apabila ukuran kotak (stup) tidak sesuai atau besar seringga menghasilkan madu yang sedikit karena ukuran yang besar memiliki rongga tidak rapat seringga semut bisa masuk.

3. Jenis lebah Trigona spp yang dibudidayakan pada Kelompok Tani Hutan Madu Kelulut Galang berjumlah 2 jenis yaitu $H$. itama Cockerel, dan H. bakeri.

4. Pengolahan madu kelulut (Trigona spp) akan menguntungkan yang besar dari jasa madu kelulut (Trigona spp). Pemanenan madu kelulut dari para petani madu adalah sebesar 15 - 30 liter/bulan. Harga yang di jual untuk para konsumen adalah sekitar Rp 400.000 untuk setiap 1 liter.

\section{SARAN}

Hasil penelitian ini diharapkan mampu memberikan informasi kepada 
masyarakat sekitar agar dapat menjaga hutan dari titik api dari hutan gambut karena mudah terbakar yang dapat memicu kebakaran hutan, dikarenakan lebah kelulut sangat sensitif terhadap adanya asap.

\section{DAFTAR PUSTAKA}

Awaludin, 2018. Biologi dan Identifikasi Serta Prospek Usaha Trigona spp. di Kebun Raya Universitas Halu Oleo. Jurnal Buletin, 20(2), 14104466

Dewantari M. 2019. Pengembangan Budidaya Lebah Madu Trigona spp Ramah Lingkungan Di Desa Antapan Kecamatan Baturinti Babupaten Tabanan. Jurnal Udayana, Vol 18 No 1

Corlett, R. T. 2011. Honeybees in natural ecosystems. In: Honeybees of Asia. R. Hepburn and Sarah E. Radolf (Eds). Springer, Berlin Heidelberg. pp. 215-225

Gebremariam, T., Brhane, G.2014, Determination Of Quality And Adulteration Effects Of Honey From Adigrat And Its Surrounding Areas. International Journal of Technology Enhancements And Emerginng Engineering Research, 2, 2347-4289.

Iqbal M, Defri Y, Budiani ES. 2016. Karakteristik Habitat Trigona spp.
Di hutan Larangan Adat Desa Rumbio Kabupaten Kampar. Jom Feperta UR Vol 3 No 2

Mahani, Karim, R.A. \& Nurjanah, N., 2011. Keajaiban Propolis Trigona. Jakarta: Pustaka Bunda.

Radam, R. 2011. Prodivitas dan Kontribusi Peternakan Lebah madu Terhadap Pendapatan Masyarakat di Desa Muarah Pemangkih Kabupaten Hulu Sungai Tengah. Jurnal Hutan Tropis, Vol 12 No 32.

Romi Wardoyo, Analisis Kelayakan Usaha Ternak Lebah Madu Jaya Makmur (di Desa Jono Oge Kecamatan Sigik Biromaru Kabuaten Sigi Sulawesi Tengah), Jurnal Agrotekbis, 4 (1), 84-90.

Syafrizalf Taringan D, Yusuf R, 2014. Keragaman dan habitat lebah Trigona pada Hutan sekunder Tropis basah di hutan Pendidikan Lempake, Samarinda, Kalimatan Timur. Jurnal Teknologi Pertanian, 9(1), 34-38

Kerisna, V. 2019. Identifikasi Jenis Lebah Trigona spp Pada Zona Pemanfaatan hutan desa Menua Sadap kecamatan Embaloh Hulu Kabupaten Kapuas Hulu. Jurnal Tengkawang, 9 (2), 82-91. 